\title{
Desenvolvimento de um projeto de implementação de aulas experimentais no Colégio de Aplicação João XXIII (UFJF): implicações para o ensino, a pesquisa e a extensão
}

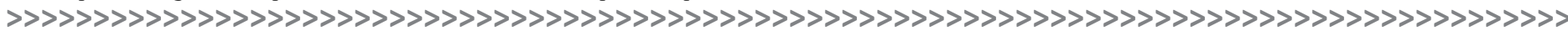

Fernanda Bassoli*

Érica Maria Nascimento Dias**

Márcia Fernandes Pinheiro Hara**

Thamiris Dornelas de Araújo ${ }^{* * *}$

\begin{abstract}
Resumo:
O presente artigo relata o desenvolvimento de um projeto de inserção de aulas experimentais no currículo de Ciências Naturais das turmas do segundo segmento do Ensino Fundamental no Colégio de Aplicação João XXIII (UFJF). A motivação do projeto perpassa a importância da experimentação na aprendizagem de Ciências, visando potencializar as aulas experimentais anteriormente realizadas, além da possibilidade de ampliação quantitativa de tais aulas. Nesse sentido, houve a divisão das turmas para a realização de dinâmicas experimentais. Proporcionou-se, dessa forma, maior segurança no laboratório, bem como maior interação entre os estudantes e os experimentos (hands on, minds on, hearts on, social on). Verifica-se que o projeto gera resultados positivos no ensino de ciências do colégio, com o desenvolvimento de uma cultura científica, além de repercutir no campo da pesquisa e da extensão, com destaque para a formação inicial e continuada de professores.
\end{abstract}

\section{Palavras-chave:}

Aulas experimentais. Ensino de Ciências Naturais. Alfabetização científica. Ensino por investigação. Cultura científica.

\begin{abstract}
:
The present article reports the development of an experimental class project in the curriculum of Natural Sciences in the Elementary School at Colégio de Aplicação João XXIII (UFJF). The motivation of the project contemplates the importance of experimentation in the learning of Sciences, and also emphasizes the potential of the experimental classes, which were prior to the project and had its quantitative amplified by the proposal presented here. In that sense, classes were divided into groups and the security in the Natural Science Laboratory was reinforced, as part of an strategy to guarantee a better interaction among the students doing the experiments (hands on, minds on, hearts on, social on). This project presents a positive impact on the teaching of Natural Sciences in the school, with the development of a scientific culture, besides having repercussions in the field of researching and extension, with emphasis on initial and continuing teacher training.
\end{abstract}

\section{Keywords:}

Experimental classes. Teaching of Natural Sciences. Scientific literacy. Research Teaching. Scientific culture.

\footnotetext{
* Mestre em Ecologia. Doutora em Química. Professora do CAp João XXIII/UFJF. Disciplina: Ciências e Biologia. E-mail: fernanda.bassoli@ufjf.edu.br.

** > Mestre em Ciências Biológicas-Comportamento e Biologia Animal. Professora do CAp João XXIII/UFJF. Disciplina: Ciências e Biologia. E-mail: ericamjf@gmail.com.

*** > Mestre em Educação. Professora do CAp João XXIII/UFJF. Disciplina: Ciências e Biologia.

E-mail: marciapinheirohara@gmail.com.
} 


\section{Introdução e Referenciais Teóricos}

Existe um amplo consenso da comunidade científica acerca da importância e necessidade de se proporcionar a todos os cidadãos a tão conclamada alfabetização científica (CACHAPUZ et al., 2005). Apesar da pluralidade de concepções que permeiam a alfabetização científica, há, segundo os autores, uma convergência sobre a necessidade de ir além da habitual transmissão de conhecimentos científicos, para incluir uma aproximação entre a natureza da ciência e a prática científica. Enfatiza-se, sobretudo, as relações entre ciência, tecnologia, sociedade e ambiente, com intuito de favorecer a participação dos cidadãos na tomada de decisões (AIKENHEAD, 1985 apud CACHAPUZ et al., 2005).

Nessa perspectiva, as pesquisas em didática de ciências têm apontado para a necessidade de se superar o reducionismo conceitual. Busca-se, nesse sentido, aproximar o ensino das ciências à investigação científica em seus aspectos conceituais, procedimentais, axiológicos e epistemológicos. Tal preocupação mobiliza-nos a buscar estratégias para promover a imersão de nossos alunos em uma cultura científica, visando a envolver os estudantes nas diferentes dimensões dessa cultura. Assim, a promoção das atividades de experimentação situa-se como uma das estratégias que desenvolvemos para tal.

Cabe, portanto, esclarecer o que se considera como atividade experimental ou de experimentação. Segundo Andrade e Massabni (2011, p. 840) as atividades práticas são entendidas como "[...] aquelas tarefas educativas que requerem do estudante a experiência direta com o material presente fisicamente, com o fenômeno e/ou com dados brutos obtidos do mundo natural ou social". Para esses autores, o aspecto central é a presença material dos objetos, espécimes ou fenômenos a serem investigados, independentemente do tipo de contato que os estudantes estabelecem com eles, podendo inclusive, prescindir do contato direto por parte dos alunos, como acontece nas atividades práticas demonstrativas.

Porém, defendemos que as atividades práticas sejam planejadas de forma a propiciar diferentes formas de interatividade dos estudantes com os objetos e fenômenos, bem como entre os próprios estudantes e seus professores. Assim, promove-se, sempre que possível, a interação direta dos alunos com os objetos e fenômenos (hands on), a reflexão (minds on), o vínculo emocional (hearts on) e as interações sociais (social on) (BASSOLI, 2014). Vale destacar que esta estratégia favorece a construção de significados pelos estudantes, contribuindo, dessa forma, para uma aprendizagem significativa (MOREIRA, 2012).

Nesta perspectiva, diante das diferentes "modalidades" de atividades práticas, nosso projeto visa a desenvolver experimentos investigativos (CAMPOS; NIGRO, 1999), aqui denominados atividades experimentais ou de experimentação, dadas as suas potencialidades em contribuir para o desenvolvimento de uma cultura científica e da superação de uma "visão deformada sobre ciência" (CACHAPUZ et al., 2005). Francisco Jr. et al. (2008) destacam a importância de elaborar experimentos que busquem estreitar o laço entre motivação e aprendizagem, principalmente por meio de uma experimentação problematizadora, a qual propicia aos estudantes manipular, registrar, refletir, levantar e avaliar hipóteses.

Os experimentos investigativos são caracterizados por envolver discussão de ideias, elaboração de hipóteses explicativas e experimentos para testá-las. Exige-se, portanto, grande participação do aluno durante sua execução (CAMPOS; NIGRO, 1999). Nesse sentido, este tipo de atividade estimula, potencialmente, os quatro tipos de interatividade supracitados, contribuindo para a aprendizagem de conceitos, procedimentos e atitudes (BRASIL, 1998).

Nos Parâmetros Curriculares Nacionais, PCN (BRASIL, 1998) preconiza-se, além dos conteúdos conceituais, a aprendizagem de procedimentos e atitudes como uma das formas de trabalhar os conteúdos em Ciências Naturais $(\mathrm{CN})$. O conteúdo procedimental, segundo os PCN, expressa um saber fazer que envolve tomar decisões e realizar ações para se atingir uma meta. Nesse contexto, inserem-se a pesquisa e o experimento como 
proposições de ações que podem ser desenvolvidas. O documento também destaca diferentes métodos ativos como a utilização de observações, jogos, além de diferentes fontes textuais para obter e comparar informações, cuja finalidade é despertar o interesse dos estudantes pelos conteúdos e ampliar o processo de construção de significados.

De modo semelhante, a Base Nacional Comum Curricular, BNCC (BRASIL, 2017), na área de Ciências da Natureza, visa a assegurar aos alunos do Ensino Fundamental o acesso à diversidade de conhecimentos científicos produzidos ao longo da história, bem como a aproximação gradativa aos processos, às práticas e aos procedimentos da investigação científica. Assim, segundo este documento, é imprescindível que os alunos sejam progressivamente estimulados no planejamento e na realização cooperativa de atividades investigativas.

Embora os PCN e a BNCC enfatizem a importância do desenvolvimento de atividades experimentais, a falta de recursos e infraestrutura, assim como problemas na formação dos professores ou condições de trabalho desfavoráveis, resultam na ausência de tais atividades, na maioria das escolas públicas brasileiras (ANDRADE; MASSABNI, 2011). Não obstante, os colégios de aplicação (CAp) são locais privilegiados para a realização de tais atividades, visto que reúnem infraestrutura adequada, condições favoráveis de trabalho e de formação para os docentes. Para melhor contextualização do projeto, apresentaremos a seguir um pouco da história e caracterização do CAp João XXIII.

\section{Contextualizando o Colégio de Aplicação João XXIII}

O Ginásio de Aplicação João XXIII, como eram denominados os Colégios de Aplicação pelo Decreto lei no 9.053 de 1946 (BRASIL, 1946), foi criado em 1965, pelo professor Murílio de Avellar Hingel, ex-Ministro da Educação, como "uma escola de experimentação, demonstração e aplicação", para atender aos licenciandos em termos de pesquisa e realização de estágios supervisionados. Com o tempo, o colégio foi adquirindo maior autonomia, desvinculando-se, em 1989, da Faculdade de Educação e ligando-se, administrativamente, à Pró-reitoria de Ensino e Pesquisa, atual Pró-reitoria de Graduação, para somente em 1998 tornar-se uma Unidade Acadêmica da Universidade Federal de Juiz de Fora.

Desde sua criação até os dias atuais, os Colégios de Aplicação vêm se modificando, tendo hoje em dia, como objetivos fomentar: educação básica, desenvolvimento da pesquisa; experimentação de novas práticas pedagógicas; formação de professores; criação, implementação e avaliação de novos currículos e capacitação de docentes. Os Colégios de Aplicação também devem ser um local de investigação, pois devem "[...] criar um ambiente propício para uma variedade de pesquisas que possam ser realizadas por professores do ensino fundamental e médio, professores universitários, estagiários e outros" (UFMG, 2017, s.p.).

O ingresso dos alunos no CAp João XXIII ocorre por meio de sorteio público anual para o ensino regular e para a Educação de Jovens e Adultos (EJA), garantindo-se a democratização do acesso às vagas e favorecendo a diversidade. Atualmente, o CAp conta com cem docentes, trinta e seis técnicos administrativos e cerca de mil e duzentos alunos, matriculados em vinte e oito turmas de Ensino Fundamental, nove turmas de Ensino Médio regular e seis turmas de Ensino Médio da EJA.

Tendo em vista a excelente infraestrutura do colégio, corpo docente altamente qualificado, constituído por professores mestres e doutores e, principalmente, a qualidade da formação oferecida, a demanda da sociedade pelas vagas é muito alta. 


\section{Concepção e desdobramentos do projeto}

O desenvolvimento do projeto de aulas experimentais para o segundo segmento do Ensino Fundamental foi motivado pela percepção por parte das professoras de $\mathrm{CN}$ da necessidade de se melhorar a organização e a produtividade deste tipo de aula. Apesar do CAp apresentar uma boa estrutura de laboratórios, a presença de mais de trinta alunos nesse espaço não favorece a interatividade dos alunos com os experimentos e equipamentos, tendo em vista, por exemplo, as dificuldades para se fazer uma atividade de observação de microscopia ou lidar com reagentes.

Dessa forma, as professoras decidiram dedicar uma aula quinzenal às atividades práticas, oferecendo aos alunos a oportunidade de observar, experimentar, criar hipóteses e testá-las nas aulas de ciências, bem como de discutir em grupos os resultados dos experimentos, promovendo aulas que se aproximassem mais à perspectiva investigativa.

Para tal, desde o início de 2018, quando o projeto foi implementado, as turmas são divididas em dois grupos para a realização destas aulas, de modo que uma professora de ciências apoie a outra. Enquanto uma parte da turma faz suas atividades com a professora regente da turma, no laboratório, a outra professora, de apoio, desenvolve atividades paralelas em sala de aula, elaboradas pela professora regente. Na semana seguinte, os grupos se invertem e a professora regente leva a segunda metade da turma ao laboratório, enquanto a professora de apoio fica em sala desenvolvendo com os demais alunos as atividades propostas pela regente. Esse processo é desenvolvido em todas as turmas do sexto ao nono ano, sendo que cada uma das quatro professoras de ciências do colégio é professora regente de um ano escolar e também professora de apoio das turmas de uma de suas colegas.

Por meio do projeto, foi possível estabelecer uma rotina de aulas no laboratório e, principalmente, garantir aos alunos uma maior interação com os experimentos, com as professoras e com os demais estudantes durante as atividades experimentais, potencializando o processo de aprendizagem de conceitos, procedimentos e atitudes e contribuindo para a alfabetização científica.

As aulas experimentais desenvolvidas no CAp João XXIII são pautadas pelo estímulo ao interesse e à curiosidade científica, no sentido de que possibilitam aos estudantes definir problemas, levantar hipóteses, analisar e representar os resultados, comunicar conclusões e propor intervenções, conforme recomendado pela BNCC. Dessa forma, buscamos estimular a curiosidade dos alunos, contribuindo para a sua alfabetização científica num aspecto amplo que envolva, além da apreensão contextualizada de conceitos, o desenvolvimento de atitudes voltadas para a colaboração e transformação social.

Os roteiros de aulas práticas elaborados pelas professoras de CN do CAp João XXIII inserem-se neste contexto, na medida em que abrem espaço para que $o$ aluno registre suas observações (por escrito ou por meio de ilustrações) após discussão em grupo do que foi observado e responda a questionamentos elaborados pelo professor para desafiá-lo, com reflexão, elaboração de hipóteses, avançando-se, assim, na construção do conhecimento.

Outro aspecto importante no que tange à organização e execução das atividades práticas é a preocupação em replicar os experimentos de forma que os alunos possam, eles mesmos, manusear os equipamentos e o material e realizar o experimento em grupos, o que estimula o trabalho em equipe e promove a construção coletiva do conhecimento. Após discussão e registro das observações nos grupos, os alunos são estimulados a expor oralmente seus questionamentos e suas hipóteses, o que favorece não só o trabalho em equipe, mas também a colaboração entre equipes, defendida por Giordan (1999), que ressalta que a formação de um espírito colaborativo de equipe pressupõe uma contextualização socialmente significativa para a aprendizagem, tanto do ponto de vista da problematização quanto da organização do conhecimento científico. 
Soma-se a isso a estratégia didática de realizar as aulas práticas em turmas com um quantitativo menor de alunos. Desse modo, o professor passa a ter maior controle sobre o manuseio do material, de forma a garantir a segurança com relação ao desenvolvimento do procedimento experimental e torna a relação professor-aluno mais próxima, facilitando a mediação das discussões e estimulando a participação mais efetiva de cada aluno em todo o processo. Segundo Pereira (2010), a ajuda pedagógica do professor é essencial para que haja intervenções e proposições que contribuam para os processos interativos e dinâmicos que caracterizam a prática experimental de ciências. $\mathrm{O}$ autor também defende que essa mediação do professor deve extrapolar a observação empírica, problematizando, tematizando e contextualizando o experimento.

Vale destacar a participação de estagiários dos cursos de licenciatura em Ciências Biológicas e Química, bem como de bolsistas do Programa Institucional de Iniciação à Docência (PIBID), os quais têm contribuído para qualificar ainda mais o projeto, como também têm sido beneficiados com os conhecimentos construídos a partir do planejamento de atividades e das interações estabelecidas com os estudantes e com as professoras. Nessa perspectiva, trata-se de contribuições significativas para o processo de formação inicial docente.

\section{Desdobramentos do projeto: do ensino à pesquisa e extensão}

O projeto de desenvolvimento de aulas experimentais tem despertado grande interesse e motivação nos estudantes para a aprendizagem de $\mathrm{CN}^{1}$. Um dos seus impactos mais visíveis é a elevação da qualidade dos trabalhos que têm sido desenvolvidos pelos estudantes na Mostra de Trabalhos da Semana de Ciências e Matemática, como também em eventos realizados pela UFJF. Como resultado do trabalho desenvolvido nas aulas de CN, em 2018, dois grupos de estudantes foram premiados na Feira de Ciências promovida pelo Instituto de Ciências Exatas da UFJF², além de apresentarem um trabalho no Seminário UFJF Sustentável ${ }^{3}$, evento que reuniu majoritariamente graduandos e professores da UFJF, visando ao compartilhamento de experiências sustentáveis.

Além dos impactos percebidos na motivação dos estudantes, na aprendizagem e no desenvolvimento de uma cultura científica na escola, o projeto tem gerado um conjunto de roteiros de aulas experimentais e, principalmente, vem proporcionando a construção de uma vasta gama de saberes relacionados à experimentação, ao desenvolvimento e à construção de conteúdos científicos e ao trabalho colaborativo das professoras.

Diante do potencial das ações desenvolvidas no referido projeto, ampliaram-se as perspectivas de ações a serem implementadas. Assim, as professoras decidiram criar um grupo de estudos, que possibilita planejamento, reflexão sobre as ações realizadas e partilha de conhecimentos. Em consequência e juntamente com o grupo, surgiram propostas de diferentes frentes que vieram por se transformar em três projetos de extensão submetidos e aprovados em 2018:

" O Projeto Ciência Lúdica: criação e compartilhamento de jogos voltados para o ensino de ciências, o qual tem como objetivo o desenvolvimento e a confecção de jogos didáticos sobre diversos temas no campo das CN (tabuleiro, cartas, dominó, entre outros), partindo-se das necessidades identificadas ao longo do processo de ensino e aprendizagem. Todo material é pensado com foco na praticidade, reprodutibilidade e no baixo custo, com o objetivo de se atingir o maior número de realidades possíveis.

" O Projeto Sustentabilidade: da reflexão para a ação tem como objetivo ampliar a discussão e a conscientização acerca de temas como o consumismo e as práticas sustentáveis, num trabalho realizado dentro e fora de sala de aula, envolvendo os
1 > Disponível em: http://www.uffi.br/ joaoxxiii/2018/07/31/alunos-aprendemconceitos-de-quimica-com-robo/. Acesso em: 09 jun. 2019.

2 > Disponível em: http://www.ufjf.br/ joaoxxiii/2018/10/19/alunos-do-joao-xxiii-participam-de-feira-de-ciencias-do-ice/. Acesso em: 09 jun. 2019.

3 > Disponível em: http://www.ufjf.br/ joaoxxiii/2018/12/12/alunos-do-joao-xxiii-apresentam-trabalho-no-ufj-sustentavel/. Acesso em: 09 jun. 2019. 
estudantes e suas famílias, que discutem e participam de todo o processo a partir de encontros mensais. Os alunos ajudaram na criação de uma composteira, cujo composto está sendo utilizado na adubação de uma horta instalada no colégio.

" O Projeto Laboratório na rede: socializando saberes na experimentação em ensino de ciências: tem por objetivo produzir e divulgar vídeos simples e diretos acerca das possibilidades de experimentação no ensino de $\mathrm{CN}$, construídos a partir de adaptações de protocolos, concepções pedagógicas e demandas do CAp. Trata-se de construções direcionadas ao professor, que poderá valer-se de todo o conteúdo para buscar adaptações que o permitam desenvolver aulas experimentais produtivas e utilizando materiais de fácil acesso.

Todos os projetos de extensão ancoram-se em uma proposta maior, que é a socialização das ações e práticas pedagógicas construídas e aperfeiçoadas nos projetos. Disponibilizam-se ainda os materiais produzidos (roteiros de aulas práticas, vídeos, jogos, relatos de experiência e produções científicas do grupo) em mídias digitais e gratuitas. Assim, é possível alcançar um número maior de profissionais que, na busca pela troca de experiências ou por inspiração para a construção de suas aulas, tenham a oportunidade de aperfeiçoar e refletir sobre sua prática. Essa proposta traduziu-se no Programa de Extensão Mídias digitais e socialização dos saberes e práticas docentes em ciências naturais desenvolvidas no Colégio de Aplicação João XXIII.

A partir da divulgação dos materiais em site institucional ${ }^{4}$, o programa poderá valerse de dados de acesso e engajamento como ferramentas fundamentais para o entendimento do comportamento do professor como usuário de internet, bem como para a reflexão das próprias práticas desenvolvidas no colégio, oportunizando novas construções de saberes.

Atualmente, os projetos e o programa de extensão contam com a colaboração de seis bolsistas de graduação, sendo dois estudantes de biologia, um estudante de artes e design, um de jornalismo, um de geografia e um de pedagogia. Os bolsistas contribuem ativamente na construção das propostas e metas de todos os projetos, avaliando resultados, produzindo materiais pedagógicos e acrescentando ao grupo informações valiosas relativas às suas áreas de atuação, o que torna o ambiente de criação e análise extremamente rico para todos os discentes e docentes. Além da produção de conhecimento pedagógico, fruto das reflexões acerca do ensino de ciências, com aplicações dentro e fora do CAp e da possibilidade de acrescentar experiências enriquecedoras à formação do público-alvo final (professores em formação inicial e continuada), os projetos possibilitam a aplicação de conhecimentos relativos ao design, ao marketing digital e ao gerenciamento de conteúdo na internet, que são pouco comuns em ambientes escolares, mas que são úteis na profissionalização do trabalho de produção dos materiais e sua divulgação.

Nossa visão acerca da possibilidade de socialização dos saberes em mídias digitais, materializada no Programa de Extensão, faz cumprir, de forma moderna e com novas possibilidades de avaliação, o papel dos Colégios de Aplicação, que é o de refletir sobre práticas de ensino inovadoras e produzir conhecimento, contribuindo para a formação profissional de professores e outros agentes, oferecendo aos seus alunos experiências e possibilidades de construção de saberes visando à alfabetização científica e valendo-se das relações de troca de experiências como ferramenta para a construção de novas práticas.

Dessa forma, a necessidade de realização de pesquisas sobre as implicações dos projetos para a aprendizagem de $\mathrm{CN}$ ocasionou a ampliação do grupo de estudos inicial para um grupo de pesquisa, que está voltado a pesquisas sobre o currículo de $\mathrm{CN}$, processos

4 > Disponível em: http://www.ufjf.br/ ciensinar/. Acesso em: 09 jun. 2019.

5 > Disponível em: http://www.ufjf.br/ ciensinar/publicacoes-2018/. Acesso em: 09 jun. 2019. de ensino-aprendizagem de $\mathrm{CN}$ e formação de professores, cujas primeiras produções 5 foram divulgadas no fim de 2018.

O desenvolvimento do projeto de aulas experimentais tem provocado no grupo novas inquietações como: Quais os impactos das aulas experimentais na aprendizagem de conceitos científicos e na motivação dos estudantes? Quais os temas estruturantes das 
Ciências Naturais e como eles podem ser trabalhados de forma recursiva ao longo da Educação Básica? - entre outras questões que vêm impulsionando o grupo para novas perspectivas de trabalho no campo da pesquisa. Nessa direção, o grupo abre uma nova frente de trabalho por meio da participação em um projeto inovador no campo do desenvolvimento profissional docente: o projeto Residência Docente ${ }^{6}$. Com a participação da nossa equipe no programa de residência, temos como horizonte não apenas contribuir para o processo de desenvolvimento profissional dos residentes, como também desenvolver pesquisas colaborativas que nos permitam avaliar nossas ações e produzir conhecimentos sobre o currículo, ensino e aprendizagem de conceitos estruturantes para o ensino das CN.

\section{Considerações finais}

Discutimos neste artigo a importância de promovermos diferentes formas de interatividade dos estudantes com os objetos e fenômenos em estudo, bem como entre os próprios estudantes e os docentes, de modo a favorecer a construção de significados. Nessa direção, destacamos as aulas experimentais investigativas, tendo em vista seu maior potencial em contribuir para o desenvolvimento de uma cultura científica e da superação de uma "visão deformada sobre ciência".

Tendo em vista a necessidade de se realizar com maior frequência este tipo de aula e com um menor número de alunos, a implementação do projeto de aulas experimentais com turmas divididas, no CAp João XXIII, descrito neste artigo, vem trazendo diversos desdobramentos positivos para o processo de ensino e aprendizagem de $\mathrm{CN}$, como maior controle sobre o manuseio do material de forma a garantir a segurança dos alunos; maior interação entre o docente e os alunos, facilitando a mediação das discussões e, principalmente, estimulando a participação mais efetiva de cada aluno em todo o processo.

Desde a implantação do projeto, em 2018, as aulas experimentais têm sido pautadas pelo estímulo ao interesse e à curiosidade científica, possibilitando aos estudantes definir problemas, levantar hipóteses, analisar e representar os resultados, comunicar conclusões e propor intervenções. Dessa forma, buscamos contribuir para a alfabetização científica dos estudantes, propiciando a apreensão contextualizada de conceitos, o desenvolvimento de habilidades e procedimentos relacionados à cultura científica e de atitudes voltadas à colaboração e transformação social.

O projeto tem despertado grande interesse e motivação nos estudantes para a aprendizagem de $\mathrm{CN}$, repercutindo na qualidade dos trabalhos que têm sido desenvolvidos por eles nos eventos científicos promovidas pela escola e pela universidade, contribuindo de forma significativa para a aprendizagem e para o desenvolvimento de uma cultura científica na escola.

Além dos impactos sobre a prática docente, o projeto vem proporcionando a construção de uma vasta gama de saberes relacionados à experimentação, ao desenvolvimento e à construção de conteúdos científicos e ao trabalho colaborativo pelas professoras envolvidas no projeto, como também para os estagiários, bolsistas e residentes. Tais construções têm aperfeiçoado e integrado continuamente as reflexões e práticas do grupo de docentes do CAp, além de permitir uma troca de experiências que se estende para além do grupo de trabalho local e impacta positivamente a comunidade escolar.

Além das contribuições para a formação dos estudantes e professores, o projeto teve repercussões no campo da pesquisa e da extensão, visto que tem gerado um conjunto de roteiros de aulas experimentais, vídeos, jogos e relatos de experiência que estão sendo disponibilizados por meio do site do programa de extensão Ciensinar. Tal programa abriu novas perspectivas para o grupo, tendo em vista a necessidade de realização de pesquisas
$6>$ Trata-se de um projeto institucional da UFJF, desenvolvido pela Pró-reitoria de Graduação, Pró-reitoria de Pós-Graduação e Pesquisa, CAp. João XXIII, Faculdade de Educação e Institutos formadores de professoras(es) da UFJF, que tem como objetivo central aprimorar a formação da(o) professora(or) da Educação Básica, a partir da oferta de um programa de formação continuada na forma de curso de Especialização, que visa ao desenvolvimento de competências docentes a partir da vivência em um ambiente escolar de reconhecida excelência, de forma a contribuir para a elevação do padrão de qualidade da Educação Básica. Dessa forma, professores recém-formados das diferentes áreas do conhecimento farão uma imersão como residentes no Colégio, sendo supervisionados e orientados por professores do CAp. 
sobre as implicações dos projetos em curso no CAp para a aprendizagem de CN, dando origem ao Grupo de Estudos e Pesquisas Ciensinar, cadastrado no Diretório de Grupos do CNPq, que está voltado para pesquisas sobre o currículo, processos de ensino-aprendizagem e formação de professores de $\mathrm{CN}$. Ainda há muito o que fazer, mas todas as ações e os desdobramentos aqui colocados reforçam a imagem do CAp João XXIII como um espaço de formação de professores, de reflexão e inovação, de pesquisa e promoção de um ensino de CN capaz de formar indivíduos autônomos e conscientes do papel e da importância da ciência na sociedade.

\section{Referências}

AIKENHEAD, Glen S. Collective decision making in the social context of science. Science Education, v. 69, n. 4, p. 453-475, 1985.

ANDRADE, Marcelo Leandro Feitosa; MASSABNI, Vânia Galindo. O desenvolvimento de atividades práticas na escola: um desafio para os professores de ciências. Ciência \& Educação, Bauru, v. 17, n. 4, p. 835-854, 2011. Disponível em: http://www.scielo.br/pdf/ciedu/v17n4/a05v17n4.pdf. Acesso em: 21 abr. 2019.

BASSOLI, Fernanda. Atividades práticas e o ensino-aprendizagem de ciência(s): mitos, tendências e distorções. Ciência \& Educação, Bauru, v. 20, n. 3, p. 579-593, 2014. Disponível em: http://www. scielo.br/pdf/ciedu/v20n3/1516-7313-ciedu-20-03-0579.pdf. Acesso em: 14 jun. 2019.

BRASIL. Decreto-lei no 9.053, de 12 de março de 1946. Cria um ginásio de aplicação nas Faculdades de Filosofia do País. Disponível em: https://www2.camara.leg.br/legin/fed/declei/1940-1949/ decreto-lei-9053-12-marco-1946-417016-publicacaooriginal-1-pe.html. Acesso em: 02 abr. 2019.

BRASIL. Ministério da Educação. Secretaria de Educação Fundamental. Parâmetros Curriculares Nacionais. Ciências da Natureza e suas Tecnologias. Brasília, DF: MEC; SEF, 1997. 136p. Disponível em: http://portal.mec.gov.br/seb/arquivos/pdf/ciencias.pdf. Acesso em: 09 abr. 2019.

BRASIL. Ministério da Educação. Secretaria da Educação Básica. Base Nacional Comum Curricular. Brasília, DF: Ministério da Educação; SEB, 2016. Disponível em: http://basenacionalcomum.mec. gov.br/images/BNCC_EI_EF_110518_versaofinal_site.pdf. Acesso em: 09 abr. 2019.

CACHAPUZ, Antônio; GILPEREZ, Daniel; CARVALHO, Anna Maria Pessoa de; PRAIA,João; VILCHES, Amparo. A necessária renovação do ensino de ciências. 2. ed. São Paulo: Cortez, 2005.

CAMPOS, Maria Cristina da Cunha; NIGRO, Rogério Gonçalves. Didática de ciências: o ensino-aprendizagem como investigação. São Paulo: FTD, 1999.

FRANCISCO Jr., Wilmo Ernesto; FERREIRA, Luiz Henrique; HARTWIG, Dárcio Rodney. Experimentação Problematizadora: Fundamentos Teóricos e Práticos para a Aplicação em Salas de Aula de Ciências. Química Nova na Escola. no 30, p. 34-41, 2008. Disponível em: http://qnesc.sbq.org.br/ online/qnesc30/07-PEQ-4708.pdf. Acesso em: 22 abr. 2019.

GIORDAN, Marcelo. O papel da experimentação no ensino de ciências. Química Nova na Escola. no 10 , p. 43-49, 1999.

MOREIRA, Marco Antonio. ¿ Al afinal, qué es aprendizaje siginificativo?. Qurriculum: revista de teoría, investigación y práctica educativa. La Laguna, Espanha. n 25 p. 29-56, 2012. Disponível em: https://www.lume.ufrgs.br/bitstream/handle/10183/96956/000900432.pdf?sequence=1\&isAllowed=y. Acesso em: 22 abr. 2019.

PEREIRA, Boscoli Barbosa. Experimentação no Ensino de Ciências e o papel do professor na construção do conhecimento. Cadernos da Fucamp. v. 9, no 11, 2010. Disponível em: http://www. fucamp.edu.br/editora/index.php/cadernos/article/view/176. Acesso em: 26 mar. 2019.

UFMG. Centro pedagógico UFMG. Disponível em: http://www.cp.ufmg.br/index.php/colegiosde-aplicacao. Acesso em: 15 set. 2017. 